\title{
Comparison between Single- and Two-Phase Heat Transfer in a Thermally Stratified
}

Enclosure

Izumi Hagiwara ${ }^{1}$, A. Tokuhiro ${ }^{2}$, P. G. Oduor ${ }^{3}$,*

\section{Abstract}

The ratio of local Nusselt number of two-phase natural convection, $N u_{\mathrm{y}}$, two, to local Nusselt, $N u_{\mathrm{y}}$, single, number of single-phase natural convection was empirically determined. Gelatin particles were immersed in a custom-built rectangular enclosure. With one end maintained at a thermal high, the particles settling and thermal enhancement characteristics were analyzed. The value of $\eta\left(\eta=N u_{y, \text { two }} / N u_{y \text {, single }}\right)$ decreased significantly at $y / H$ (dimensionless height $)=0.03$ for all cases. The laminar-to-turbulent transition was in the range of $0.136 \leq y / H$ $\leq 0.538$ for $\Delta T_{\text {Bath }}=10{ }^{\circ} \mathrm{C}$, and $0.136 \leq y / H \leq 0.335$ for $\Delta T_{\text {Bath }}=20^{\circ} \mathrm{C}$. In general, for dualphase flow, when $\Delta T_{\mathrm{Bath}}=10{ }^{\circ} \mathrm{C}$ for particle size of $134 \mu \mathrm{m}$, there was a thermal enhancement as compared to when $\Delta T_{\text {Bath }}=20^{\circ} \mathrm{C}$, where there was a de-enhancement.

Keywords: Enhancement/de-enhancement; Nusselt number.

\footnotetext{
${ }^{1}$ Formerly at University of Missouri-Rolla (Missouri University of Science and Technology), Nuclear Engineering Department, Missouri University of Science and Technology, 222 Fulton Hall, 301 W. 14th St., Rolla, MO 65409-0170 (h19_izumi@hotmail.com)

${ }^{2}$ Akira Tokuhiro, Nuclear Engineering Dept., Idaho Falls Center for Higher Education, 1776 Science Center Drive, Ste 306, Idaho Falls, Idaho 83402 (tokuhiro@ uidaho.edu)

${ }^{3}$ Dept. of Geosciences, North Dakota State University, Fargo, ND 58108 (Peter.Oduor@ndsu.edu) *Corresponding Author
} 


\section{Introduction}

The natural convection of single- and/or dual-phases offers essential elements in studies involving thermally-derived density gradients especially in enclosures. Natural convection is observed when density gradients are present in a fluid (e.g. [1]-[7]). In single-phase convective flows there exists only the fluid that flows owing to temperature gradient. A two-phase flow is one where the second phase has the chance of moving with the convective current and settling. Heat transfer for two-phase flows introduces a myriad of factors that have to be taken into account for an exhaustive analysis. These factors can be inherent properties of the particles, like physical form, rheology, particle-particle interaction, surface characteristics, yield stress, concentration, viscosity, and change in these properties after immersion in a fluid including permeability, porosity or compressibility of sediments generated (e.g. [8]-[10]).

Suspended particles contribute heat transfer enhancement in natural convection due to a local increase in turbulence brought about by the movement of particles through the boundary layer. This mechanism has been reported by Tamari and Nishikawa [11] and Wachowiak [12] for air bubble injection in natural convection and it is explained as follows. Since the rise velocity of air bubble in suspension is larger than the convective flow, as a bubble rises near the hot wall, the bubble not only drags liquid along with it parallel to the surface, but it also pumps some of the liquid in the direction perpendicular to the hot wall. The aim of this study was to obtain local heat transfer coefficients: (i) local Nusselt numbers, $N u_{\mathrm{y}}$, (ii) local Rayleigh numbers, $R a_{\mathrm{y}}$ across the natural convection cell as a precursor in determining the efficacy of gelatin particles as an essential matrix for a dynamic filtering system.

\section{Methods}


Gelatin, a hydrophilic particle, with a dry bulk density approximately $680 \mathrm{~kg} / \mathrm{m}^{3}$ (and a measured wet density of about $1390 \mathrm{~kg} / \mathrm{m}^{3}$ ) was sieved according to an order of particle sizes. Ordered sizes were reclassified with respect to their Martin's diameter (e.g. [13-15]) determined using a SMZ800 Nikon microscope fitted with a digital camera. An enclosure (Fig. 1) made of Plexiglas, and insulated with polystyrene, was filled with approximately 20 liters of deionized/deaired water and thereafter a set volume of gelatin particles was immersed and stirred within the cell for homogeneity.

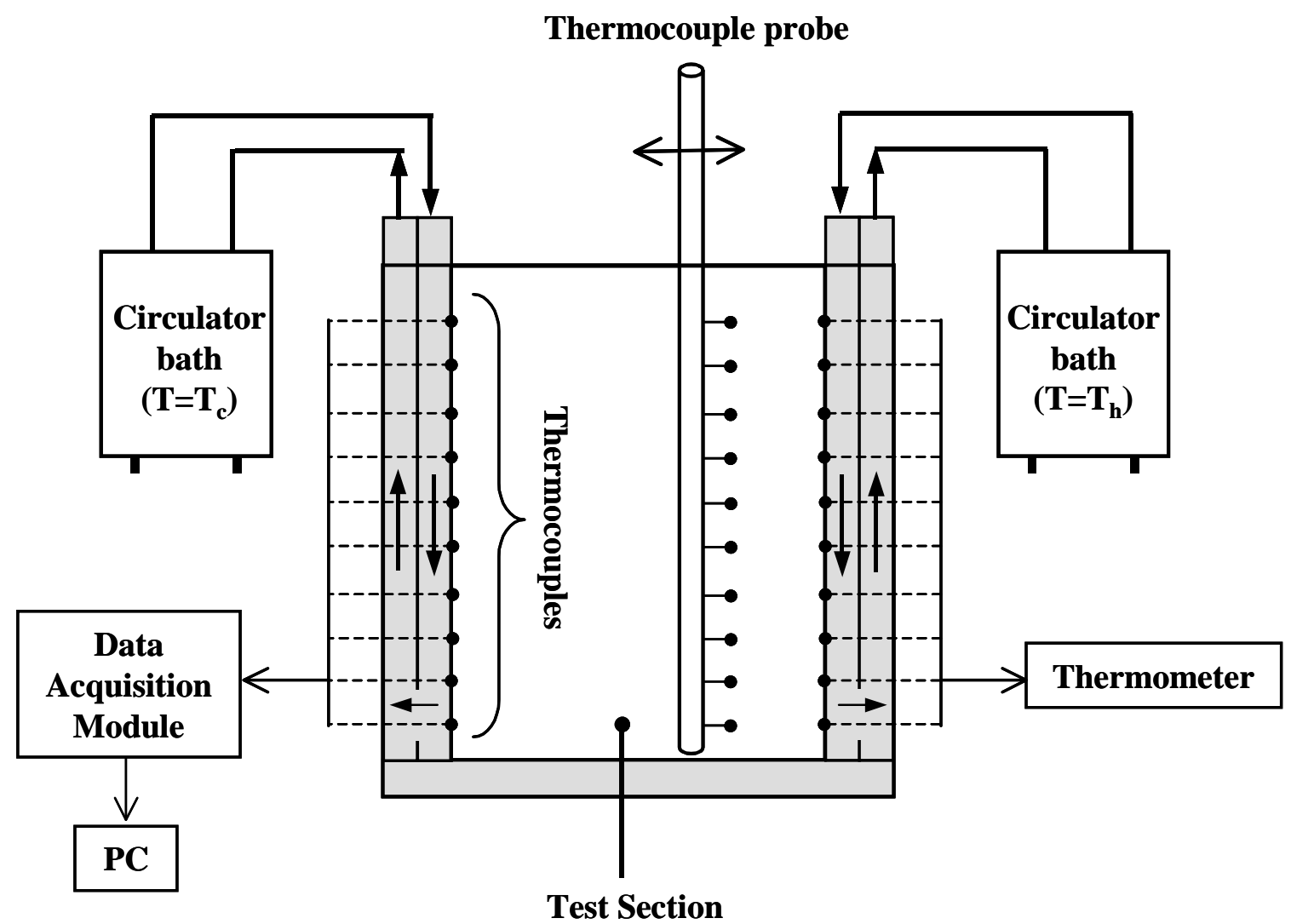

Figure 1: Schematic diagram of experimental setup (redrawn from [16]).

Suspensions of gelatin particles were prepared of average particle sizes $d_{1}=134 \mu \mathrm{m}$ and $d_{2}=230 \mu \mathrm{m}$ with weight percent loading equal to: (a) $\phi_{1}=0.026 \mathrm{wt} \%$, (b) $\phi_{2}=0.104 \mathrm{wt} \%$, (c) $\phi_{3}$ 
$=0.26 \mathrm{wt} \%$, and (d) $\phi_{4}=0.518 \mathrm{wt} \%$. To enable visibility, 18 to $24 \mu \mathrm{m}$ sized nylon seeding particles (Expancel microspheres, 091 DU 80, Akzo Nobel) were added after temperature measurements were recorded. An aluminum square channel maintained at a thermal high was connected to a LAUDA RM6 Brinkman Instruments refrigerator-heater water bath. A second setup with a PVC square channel was similarly connected to another LAUDA RM6 Brinkman Instruments refrigerator-heater system but maintained at a thermal low. At the hot $\left(20^{\circ} \mathrm{C}\right)$ end channel, were 32 AGW Chromel-Alumel thermocouples, while for the cold $\left(10^{\circ} \mathrm{C}\right)$ end, 20 AGW Chromel-Alumel thermocouples were used. All thermocouples were calibrated using a CL-307 (Omega Engineering, INC.) thermocouple calibrator. Water cycled from the aluminum channel into the PVC one in the first loop and vice versa for the second loop. Temperature was determined by measuring temperature difference between the inside and surface of the transfer tubes every quarter of an hour (cold) and every half hour (hot) until attainment of steady state ( 6 hours when differential temperature $\leq 0.2^{\circ} \mathrm{C}$ ). All temperature measurements were recorded using a data logger (Data Acquisition System - Personal Daq, IOtech). At the end of each experimental run, the sediment layer morphology and kinematics, for example, settling velocity were determined.

\section{Results and discussion}

\section{Single- and Two-Phase Heat Transfer}

In order to determine the fraction of enhancement/de-enhancement in the local Nusselt number of the natural convection due to addition of solid particles to water, the ratio of local Nusselt number of two-phase natural convection to local Nusselt number of single-phase natural convection, $\eta=N u_{y}$, two $/ N u_{y}$, single, were plotted against the dimensionless height from the 
bottom, $y / H$ (Figs. 2 - 4). The local Nusselt numbers for single-phase case were calculated from trendlines, which were obtained from single-phase experiments. Heat transfer across the convection cell is enhanced when the value of $\eta$ is greater than one or de-enhanced when $\eta$ is less than one. The laminar-to-turbulent transition is in the range of $0.136 \leq y / H \leq 0.538$ for case of bath temperature difference of $10^{\circ} \mathrm{C}$, and $0.136 \leq y / H \leq 0.335$ for $20^{\circ} \mathrm{C}$. This laminar-toturbulent transition range is shown in the figures as vertical dotted lines. Since the upper limit of the transition depends on bath temperature difference, the upper limit of transition in figures is taken as the average of the two cases.

Figure 2 shows the ratio of local Nusselt number of two-phase natural convection to local Nusselt number of single-phase natural convection with the variation for bath temperature difference of $10^{\circ} \mathrm{C}$ and $20^{\circ} \mathrm{C}$ for particle size of $134 \mu \mathrm{m}$. The horizontal axis indicates the dimensionless height from bottom of the cell; that is, the data at left give the value of $N u_{\mathrm{y}}$ along the lower section of the cell. (I) is for particle loading of $0.026 \mathrm{wt} \%$, (II) is for $0.104 \mathrm{wt} \%$, (III) is for $0.26 \mathrm{wt} \%$, and (IV) is for $0.518 \mathrm{wt} \%$. 

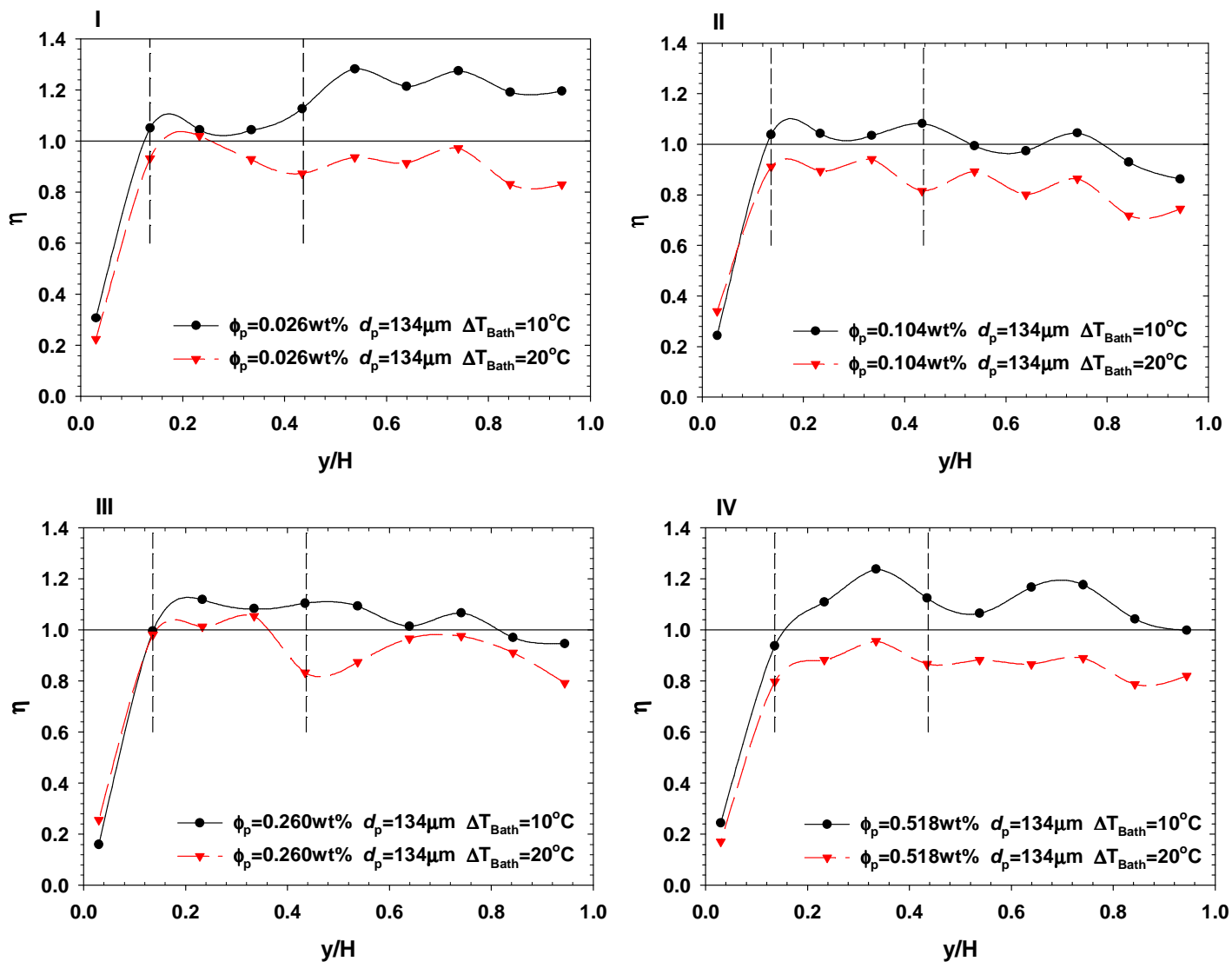

90

Figure 2. Graph of $\eta=N u_{y, \text { two }} / N u_{y}$, single, against, $y / H$ for particle size of $134 \mu \mathrm{m}$. (I)- (IV) show the variation for bath temperature difference of $10{ }^{\circ} \mathrm{C}$ and $20{ }^{\circ} \mathrm{C}$. (I) is for particle loading of $0.026 \mathrm{wt} \%$, (II) is for $0.104 \mathrm{wt} \%$, (III) is for $0.26 \mathrm{wt} \%$, and (IV) is for $0.518 \mathrm{wt} \%$. The lower the bath water temperature difference, the higher the value of $\eta$.

From Figure 2, it can be seen that the lower the bath temperature difference, the higher the value of $\eta$ for all particle loadings. The value of $\eta$ decreased significantly at $y / H=0.03$ for all cases. These reductions in local Nusselt number would be due to sediment layer of the particles. For the case of particle loading of $0.026 \mathrm{wt} \%$ (Figure 2 (I)), the sediment layer depth, divided by cell height $H$, along the center plane of the cell is $y / H=0.03$ for both cases of bath temperature difference of $10^{\circ} \mathrm{C}$ and $20^{\circ} \mathrm{C}$. For the case of particle loading of 0.104 wt $\%$ (Figure 2 (II)), the mean sediment layer depth, which is divided by cell height $H$, is 0.031 for bath temperature of $10^{\circ} \mathrm{C}$ and 0.020 for $20^{\circ} \mathrm{C}$. For case of particle loading of $0.260 \mathrm{wt} \%$ (Figure 2 
(III)), the mean sediment layer depth, divided by cell height $H$, is $y / H=0.060$ for bath temperature of $10{ }^{\circ} \mathrm{C}$ and 0.029 for $20^{\circ} \mathrm{C}$. For the case of particle loading of $0.518 \mathrm{wt} \%$ (Figure 2 (IV)), the mean sediment layer depth, divided by cell height $H$, is $y / H=0.113$ for bath temperature of $10^{\circ} \mathrm{C}$ and 0.037 for $20^{\circ} \mathrm{C}$. A large increase in the value of $\eta$ is seen for case of particle loading of $0.026 \mathrm{wt} \%$ and bath temperature difference of $10^{\circ} \mathrm{C}$ in the range of $0.5<y / H$ $<0.9$. Also there is an enhancement in $\eta$ for the case of particle loading of $0.518 \mathrm{wt} \%$ with bath temperature difference of $10^{\circ} \mathrm{C}$ at $y / H>0.136$. For bath temperature difference of $20^{\circ} \mathrm{C}$, it can be seen that the decrement in the value of $\eta$ is relatively larger in turbulent region than that in transition region.

Figure 3 shows the ratio of local Nusselt number of two-phase natural convection singlephase natural convection with the variation for bath temperature difference of $10^{\circ} \mathrm{C}$ and $20^{\circ} \mathrm{C}$ for particle size of $230 \mu \mathrm{m}$. (I) is for particle loading of $0.026 \mathrm{wt} \%$ and (II) is for $0.26 \mathrm{wt} \%$. From Figure 3, the lower the bath temperature difference, the higher the value of $\eta$. In (II), the value of $\eta$ was decreased significantly at $y / H=0.03$, but not in (I). For the case of particle loading of 0.026 wt $\%$ (Figure 4.12 (I)), the mean sediment layer depth, divided by cell height $H$, is $y / H=$ 0.016 for bath temperature of $10^{\circ} \mathrm{C}$ and $y / H=0.012$ for $20^{\circ} \mathrm{C}$. In these cases, the sediment layer lies below measurement point at $y / H=0.03$. For the case of particle loading of $0.260 \mathrm{wt} \%$ (Figure 3 (II)), however, the mean sediment layer depth, divided by cell height $H$, is $y / H=0.094$ for bath temperature of $10^{\circ} \mathrm{C}$ and 0.105 for $20^{\circ} \mathrm{C}$. There is a reduction in $\eta$ in turbulent region of $0.5<\mathrm{y} / \mathrm{H}<0.9$ for the case of particle loading of $0.026 \mathrm{wt} \%$ and bath temperature difference of $10^{\circ} \mathrm{C}$. There is a large reduction in the value of $\eta$ in case of particle loading of $0.26 \mathrm{wt} \%$ and bath temperature difference of $20^{\circ} \mathrm{C}$ at almost all values of $y / H$. 

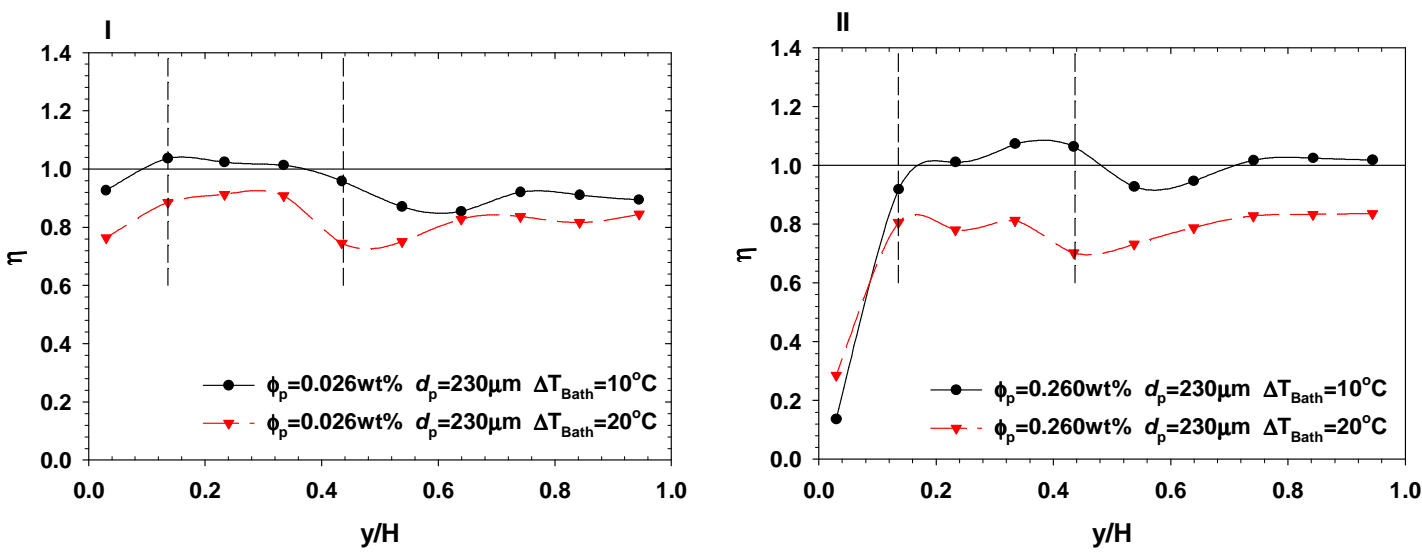

Figure 3. Graph of $\eta=N u_{\mathrm{y}, \text { two }} / N u_{\mathrm{y} \text {, single }}$ against, $y / H$ for particle size of $230 \mu \mathrm{m}$. (I) and (II) show the variation for bath temperature difference of $10{ }^{\circ} \mathrm{C}$ and $20{ }^{\circ} \mathrm{C}$. (I) is for particle loading of $0.026 \mathrm{wt} \%$ and (II) is for $0.26 \mathrm{wt} \%$. The lower the bath temperature difference, the higher the value of $\eta$. The significant reduction in $\eta$ is seen at $y / H=0.3$ for case of particle loading of 0.26 $\mathrm{wt} \%$.

Figure 4 shows the ratio of local Nusselt number of two-phase natural convection to local Nusselt number of single-phase natural convection with variation in particle size, $134 \mu \mathrm{m}$ and $230 \mu \mathrm{m}$. (I) and (III) are for bath temperature difference of $10{ }^{\circ} \mathrm{C}$, and (II) and (IV) are for 20 ${ }^{\circ} \mathrm{C}$. (I) and (II) are for the particle loading of $0.026 \mathrm{wt} \%$ and (III) and (IV) are for $0.26 \mathrm{wt} \%$.

From Figure 4, it can be seen that larger the size of gelatin particles, the lower the value of $\eta$. In the case of particle loading of $0.026 \mathrm{wt} \%$, particle size of $134 \mu \mathrm{m}$, and bath temperature difference of $10^{\circ} \mathrm{C}$ (Figure 4.13 (I)), there is a large increase in the value of $\eta$ when the value of $y / H$ is greater than 0.4 whereas for other particle loadings with same particle size and bath temperature difference, there is no increase in the value of $\eta$. In Figure 4 (II) and (IV) there is a consistently smaller value of $\eta$ for particle size of $230 \mu \mathrm{m}$. There is no significant difference in $\eta$ for particle loading of $0.260 \mathrm{wt} \%$ and bath temperature difference of $10^{\circ} \mathrm{C}$ (Figure 4 (III)), when particle size is varied. 

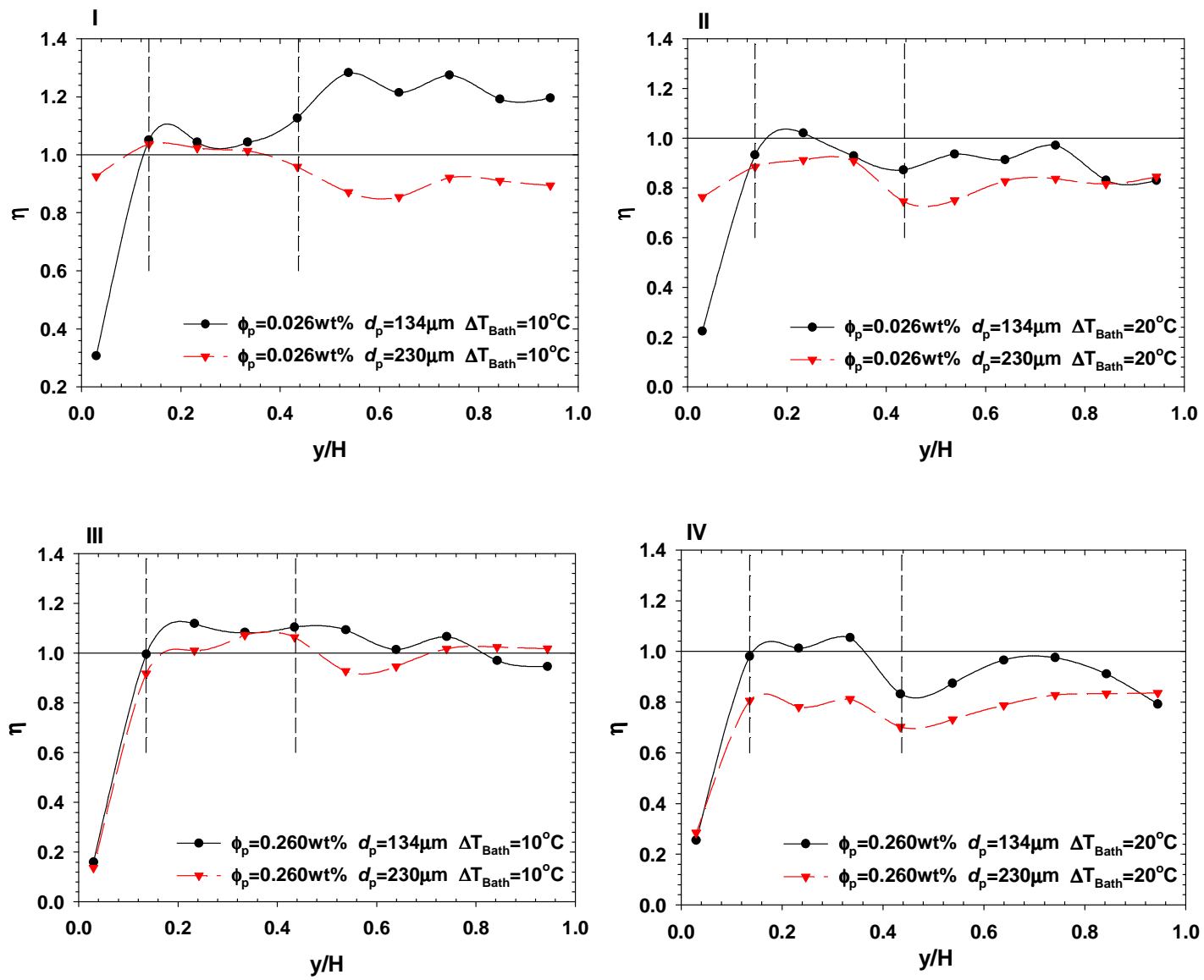

147

Figure 4. Graph of $\eta=N u_{y}$, two $/ N u_{y}$, single, against, $y / H$. (I)-(IV) show the variation for particle size of $134 \mu \mathrm{m}$ and $230 \mu \mathrm{m}$. (I) and (II) are for particle loading of $0.026 \mathrm{wt} \%$ and (III) and (IV) are for $0.26 \mathrm{wt} \%$. (I) and (III) are for bath temperature difference of $10{ }^{\circ} \mathrm{C}$ and (II) and (IV) are for $20^{\circ} \mathrm{C}$. The larger the gelatin particle size, the lower the value of $\eta$.

\section{Heat Transfer}

A comparison of heat transfer result between two-phase and single-phase natural convection can be summarized in a qualitative tabular form. The test cell was divided into three sections (1) Upper, U, (2) Middle, M, and (3) Lower, L (Figure 5). Upper section is where the particle direction changes from upward to downward at the top of the cell. For instance, a larger particle starts to sink to the bottom whereas a smaller particle can be transported to the cold end of the cell. The lower section is where the sediment layer of gelatin particles is observed. The 
section between upper and lower section is the middle section. The middle section was further subdivided into two, (a) Laminar, $\mathrm{M}_{\mathrm{L}}$, and (b) Turbulent, $\mathrm{M}_{\mathrm{T}}$, regions.

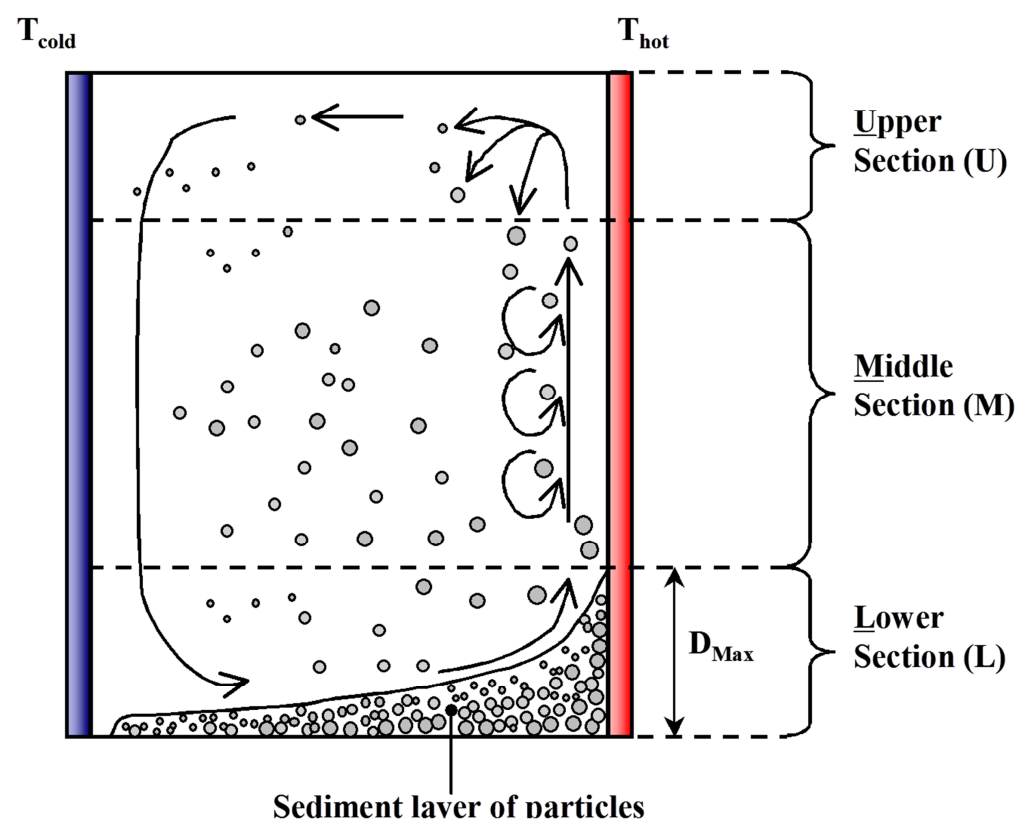

Figure 5. Sections of the natural convection cell.

Table 1 shows a summary of results from the experiments. An enhancement implies that from $\eta$ $=N u_{y, \text { two }} / N u_{y, \text { single }}>1$, and a de-enhancement the value of $\eta<1$. From Table 1 , there is generally a de-enhancement for upper section for $\Delta T_{\mathrm{Bath}}=20^{\circ} \mathrm{C}$. The lower section for both $\Delta T_{\text {Bath }}=10^{\circ} \mathrm{C}$ and $20^{\circ} \mathrm{C}$ shows a general large de-enhancement for most of the particle loadings. For the middle turbulent section when $\Delta T_{\text {Bath }}=20^{\circ} \mathrm{C}$ there is a general de-enhancement whereas for $\Delta T_{\mathrm{Bath}}=10^{\circ} \mathrm{C}$ there is an enhancement for particle loadings of $0.026 \mathrm{wt} \%$ and $0.518 \mathrm{wt} \%$ when particle size is $134 \mu \mathrm{m}$ and there is a de-enhancement for particle loading of $0.026 \mathrm{wt} \%$ when particle size is $230 \mu \mathrm{m}$. For middle laminar de-enhancement is seen for particle loadings of $0.518 \mathrm{wt} \%$ and particle size of $134 \mu \mathrm{m}$, and particle loading of $0.260 \mathrm{wt} \%$ and particle size of 
$230 \mu \mathrm{m}$ when $\Delta T_{\mathrm{Bath}}=20^{\circ} \mathrm{C}$. For $\Delta T_{\text {Bath }}=10^{\circ} \mathrm{C}$ there is no significant difference between single- and two-phase cases in the middle laminar section except for the case of particle loadings of $0.518 \mathrm{wt} \%$ and particle size of $134 \mu \mathrm{m}$.

Table 1. Summary of heat transfer results for two-phase case.

\begin{tabular}{|c|c|c|c|c|c|c|c|c|c|}
\hline \multirow{3}{*}{\multicolumn{2}{|c|}{ Section }} & \multicolumn{8}{|c|}{$\Delta T_{\text {Bath }}$} \\
\hline & & \multicolumn{4}{|c|}{$10^{\circ} \mathrm{C}$} & \multicolumn{4}{|c|}{$20^{\circ} \mathrm{C}$} \\
\hline & & U & $\mathrm{M}_{\mathrm{T}}$ & $M_{L}$ & L & U & $\mathrm{M}_{\mathrm{T}}$ & $M_{L}$ & L \\
\hline \multirow{6}{*}{$d_{\mathrm{p}}, \phi_{\mathrm{p}}$} & $d_{1}, \phi_{1}$ & $\mathrm{E}$ & $E$ & $S$ & $D_{L}$ & D & D & $S$ & $D_{L}$ \\
\hline & $d_{1}, \phi_{2}$ & D & $S$ & $S$ & $D_{L}$ & D & D & $S$ & $D_{L}$ \\
\hline & $d_{1}, \phi_{3}$ & $S$ & $S$ & $S$ & $D_{L}$ & D & D & $S$ & $D_{L}$ \\
\hline & $d_{1}, \phi_{4}$ & $S$ & $\mathrm{E}$ & $\mathrm{E}$ & $D_{L}$ & D & D & D & $D_{L}$ \\
\hline & $d_{2}, \phi_{1}$ & D & D & $S$ & $S$ & D & D & $S$ & D \\
\hline & $d_{2}, \phi_{3}$ & $S$ & $S$ & $S$ & $D_{L}$ & D & $D_{L}$ & $D_{L}$ & $D_{L}$ \\
\hline
\end{tabular}

$\mathrm{U}$ is Upper section, $\mathrm{M}_{\mathrm{T}}$ is Middle turbulent section, $\mathrm{M}_{\mathrm{L}}$ is Middle laminar section, $\mathrm{L}$ is Sediment layer section. Enhancement implies $\eta\left(=N u_{y}\right.$, two $/ N u_{y}$, single $)>1$, and de-enhancement, $\eta<1$. E is enhancement, $S$ is same as single-phase case, $D$ is for de-enhancement, and $\mathrm{D}_{\mathrm{L}}$ is for a large de-enhancement. $\phi_{\mathrm{p}}$ is particle loading for $\mathrm{p}$ $=1,2,3,4$. When $\mathrm{p}=1$, then $\phi_{1}=0.026 \mathrm{wt} \%, \phi_{2}=0.104 \mathrm{wt} \%, \phi_{3}=0.260 \mathrm{wt} \%, \phi_{4}=$ $0.518 \mathrm{wt} \%, d_{1}=134 \mu \mathrm{m}, d_{2}=230 \mu \mathrm{m}$.

\section{Error analysis}

Five sets of data were taken for each experimental run. The following sequence is an example of the error calculations performed for the temperatures and the error propagation calculations for the Nusselt number, which is derived from temperature profiles. For a given data set, the standard deviation of mean temperature, $T$, is given by: 
193 where $T_{\mathrm{i}}$ is the $i$ th measured temperature and $n$ is the total number of measurements. The error or uncertainty in the mean value, $T$, is the standard deviation of the mean or standard error, $\sigma_{m, T}$,

195 is defined to be:

$$
\sigma_{m, T}=\frac{\sigma_{T}}{\sqrt{n}}
$$

The local Nusselt number is calculated as follows:

$$
N u_{y}=\frac{h_{y} y}{k}=\frac{-\left.k \frac{d T}{d x}\right|_{x=0}}{T_{\text {hot, } \mathrm{y}}-T_{\text {bulk, } \mathrm{y}}} \cdot \frac{y}{k}
$$

In this study, temperature gradient at the hot wall, $\left.(d T / d x)\right|_{x=0}$ was obtained by fitting a function (linear, polynomial second and third order) through the data points nearest the wall and extrapolating the function to $x=0$. The values of temperature gradient at the hot wall obtained from each fitting functions (linear, polynomial second and third order) were averaged in calculation of local Nusselt number. The value of $\left.(d T / d x)\right|_{x=0}$ was highest when the second polynomial regression line was used and lowest when the third polynomial regression line was used. The value of $\left.(d T / d x)\right|_{x=0}$ obtained by linear regression line was close to the average value

of $\left.(d T / d x)\right|_{x=0}$. In error analysis, error in the value of $\left.(d T / d x)\right|_{x=0}$ obtained from linear regression method was used. In this case, the temperature gradient at the hot wall is calculated becomes: 


$$
N u_{y}=\frac{T_{\text {hot, } \mathrm{y}}-T_{x}}{T_{\text {hot, } \mathrm{y}}-T_{\text {bulk,y }}} \cdot \frac{y}{x}
$$

where $T_{x}$ is the temperature at $1 \mathrm{~mm}$ distance from the hot wall, and $x$ is the distance from the hot wall set also at $1 \mathrm{~mm}$. The standard errors were calculated for hot wall temperature, $T_{\text {hot, } \mathrm{y}}$, bulk temperature of the cell, $T_{\text {bulk, }}$, and temperature at $1 \mathrm{~mm}$ distance from the hot wall surface, $T_{x}$. The height from the bottom, $y$, corresponds to the position of the thermocouple at each setting. The distance from the hot wall, $x$, was measured by micrometer and reading could be made to the nearest $0.1 \mathrm{~mm}$.

Error propagation was calculated for the data, which was processed through subtraction, multiplication and division of measurement data. For example, the standard error of $T_{\text {hot, }}-T_{\mathrm{x}}$ is calculated as follows (e.g. [17]):

$$
\sigma_{m, T_{\mathrm{hot}, \mathrm{y}}-T_{\mathrm{X}}}=\sqrt{\left(\sigma_{m, T_{\mathrm{hot}, \mathrm{y}}}\right)^{2}+\left(\sigma_{m, T_{\mathrm{X}}}\right)^{2}}
$$

where $\sigma_{m}$ indicates the standard error for the mean value of data. Values, such as $T_{\text {hot, } y}, T_{\mathrm{x}}$ were taken as mean values of the $n$ measured values. The standard error of $T_{\text {hot, } y}-T_{\mathrm{x}} / T_{\text {hot, }}-T_{\text {bulk, y }}$, is calculated as:

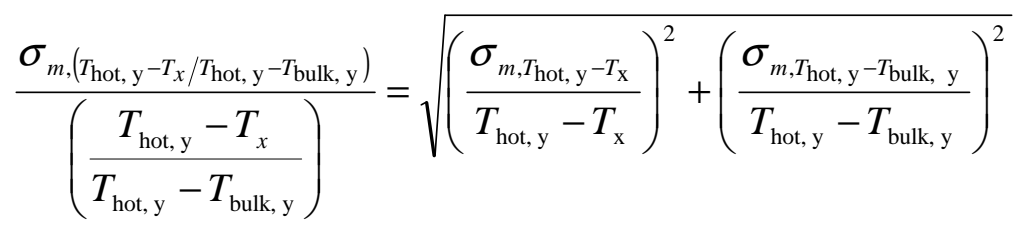

Similarly, the final error in the dimensionless local Nusselt number, $N u_{\mathrm{y}}$, can be calculated as:

$$
\frac{\sigma_{m, N u_{y}}}{N u_{y}}=\sqrt{\left(\frac{\sigma_{m, T_{\text {hot }, \mathrm{y}}-T_{\mathrm{x}}}}{T_{\text {hot, } \mathrm{y}}-T_{\mathrm{x}}}\right)^{2}+\left(\frac{\sigma_{m, T_{\mathrm{hot}, \mathrm{y}}-T_{\text {bulk, }}}}{T_{\text {hot, } \mathrm{y}}-T_{\text {bulk, }}}\right)^{2}+\left(\frac{\sigma_{m, y}}{y}\right)^{2}+\left(\frac{\sigma_{m, x}}{x}\right)^{2}}
$$


From Eq. (7) the standard errors for local Nusselt number were obtained and the errors were in the range of $10.1 \sim 18.5 \%$. The relatively large error was observed at the low Rayleigh number region where the sediment layer of particles percolated. This relatively large error was due to the fact that the local Nusselt number at this region is very small at this region. The local Rayleigh number, $R a_{\mathrm{y}}$, is calculated as follows:

$$
R a_{y}=\frac{g \beta\left(T_{h o t, y}-T_{b u l k, y}\right) y^{3}}{v \alpha}
$$

where $g$ is gravitational acceleration, $\beta$ is the thermal expansion coefficient and $v$ is the kinematic viscosity, and $\alpha$ is the thermal diffusivity. Assuming that these properties of fluid are constant during the experiment, the sources of error in calculation of $R a_{\mathrm{y}}$ are temperature difference, $T_{\mathrm{hot}}$, $\mathrm{y}^{-} T_{\text {bulk, }}, \mathrm{y}$, and height from the bottom of the cell, $y$. The standard error of $T_{\text {hot, }}-T_{\text {bulk, y }}$ is calculated by using Eq. (5). The standard error of $y^{3}$ is calculated as follows [17]:

$$
\frac{\sigma_{m, y^{3}}}{y^{3}}=3 \frac{\sigma_{m, y}}{y}
$$

where $\sigma_{\mathrm{m}, \mathrm{y}}$ has been taken as $1 \mathrm{~mm}$. The standard error of $\left(T_{\text {hot, } \mathrm{y}}-T_{\text {bulk, }}\right) \times y^{3}$ is then calculated as:

$$
\frac{\sigma_{m,\left(T_{\text {hot }, \mathrm{y}}-T_{\text {bulk, y }}\right) y^{3}}}{\left(T_{\text {hot, },}-T_{\text {bulk, }}\right) y^{3}}=\sqrt{\left(\frac{\sigma_{m, T_{\text {hot }, \mathrm{y}}-T_{\text {bulk, y }}}}{T_{\text {hot, y }}-T_{\text {bulk, }}}\right)^{2}+\left(\frac{\sigma_{m, y^{3}}}{y^{3}}\right)^{2}}
$$

241 The value of $\sigma_{m,\left(T_{\text {hot }, \mathrm{y}}-T_{\text {bulk, } y}\right) y^{3}} /\left(T_{\text {hot, } \mathrm{y}}-T_{\text {bulk, } \mathrm{y}}\right) y^{3}$ ranged from 0.003 to 0.108 . The standard error 242 of $R a_{\mathrm{y}}$ is:

$$
\sigma_{m, R a_{y}}=\left(\frac{g \beta}{v \alpha}\right) \sigma_{m,\left(T_{\text {hot }, \mathrm{y}}-T_{\text {bulk }, \mathrm{y}}\right) y^{3}}
$$


From Eq. (11) the standard errors for local Nusselt number were obtained and the errors were in

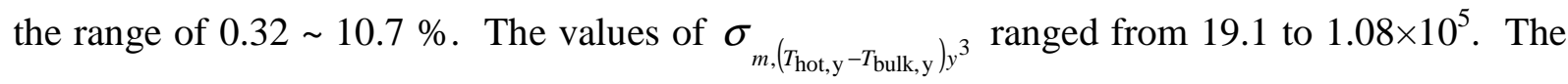
relatively large error was observed at low Rayleigh number region. This relatively large error is due to the fact that the order of $g \beta / v \alpha$, which is a product of fluid properties, is $10^{4}$. Since the order of $R a_{\mathrm{y}}$ at the bottom of cell is $10^{6}$, the standard error of $R a_{\mathrm{y}}$ becomes relatively large.

\section{Conclusions}

In this study, a gelatin particle has relatively large buoyancy when the local temperature difference is large or particle size is small. However experimental results showed that there was a heat transfer de-enhancement when temperature difference was large even when particle size was small. Also the velocity measurement showed that there was a reduction in vertical velocity for two-phase cases when temperature difference was larger. This can be due to settling motion of gelatin particles near the boundary layer. Also in this study, at the edge of the boundary layer, some medium sized-gelatin particles slowly descending to the bottom, or were swept up again into the ascending current. For the former case, the settling particle will reduce the rising particle velocity and amount of heat transported to the cold side will be reduced. Consequently, the heat transfer is de-enhanced. In the latter case, the mixing provided by the particles leads to destratification near the hot wall. Heat transfer is enhanced if the mixing takes place within the boundary layer. However if the mixing takes place outside of the boundary layer, heat transfer is de-enhanced. The latter situation is similar as the mechanism of heat transfer de-enhancement at the top of the experimental cell. In order to induce heat transfer enhancement in natural 
265 convection cell, the suspended particle has to have large buoyancy to induce turbulence and an 266 increase in this turbulence has to take place within the boundary layer.

\section{Acknowledgments}

This research was partially funded by a DOE NEER grant under contract FG0704ID14592. We would like to thank Dan Estel (MST Reactor), Jason Hall, and affiliated staff at

271 Missouri University of Science and Technology (MST) Reactor facility. We extend our 272 gratitude to Dr. David Wronkiewicz for his help. 


\section{References}

[1] Batchelor, G. K., Heat transfer by free convection across a closed cavity between vertical boundaries at different temperatures, Quarterly of Applied Mathematics, 12 (1954), pp. $209-233$.

[2] Eckert, E. R. G., Carlson, W. O., Natural convection in an air layer enclosed between two vertical plates with different temperatures, Int. J. Heat Mass Transfer 2 (1961) 106 - 120.

[3] Elder, J. W., Laminar free convection in a vertical slot, J. Fluid Mech., 23(1) (1965), pp. $77-98$.

[4] Ostrach, S., Natural Convection in Enclosures, Advances in Heat Transfer, 8 (1972), pp. $161-227$.

[5] Seki, N., Fukusako, S., Inaba, H., Visual observation of natural convective flow in a narrow vertical cavity, J. Fluid Mech., 84 (1978), pp. 695 - 704.

[6] Gill, A. E., The boundary-layer regime for convection in a rectangular cavity, J. Fluid Mech., 26 (1966), pp. 515 - 536.

[7] De Vahl Davis, G., Laminar natural convection in an enclosed rectangular cavity, Int. J. Heat and Mass Transfer, 11(11) (1968), pp. 1675 - 1693.

[8] Hoffman, A. S., Afrassiabi, A., Dong, L. C., Delivery and removal of substances to and from surrounding suspensions using thermally reversible hydrogels, Macromolecular Preprints - IUPAC Macro (1986a), pp. 65 - 66.

[9] Hoffman, A. S., Afrassiabi, A., Dong, L.C., Thermally reversible hydrogels; II. Delivery and selective removal of substances from aqueous suspensions, J. Controlled Release, 4 (1986b) pp. $213-222$.

[10] Hoffman, A.S., Applications of thermally reversible hydrogels in therapeutics and diagnostics, J. Controlled Release 6 (1987), pp. 297 - 305. 
[11] Tamari, M., Nishikawa, K., The stirring effect of bubbles upon the heat transfer, Heat Transfer Japanese Research, 5(2) (1976), pp. 31 - 44.

[12] Wachowiak, R. M., The enhancement of natural convection by rising bubbles. M.

S. Thesis, Purdue University, West Lafayette, Indiana, 1986.

[13] Phelps, G. W., Particle size analysis: theoretical and practical aspects: United Clay Mines Corporation, 1958.

[14] Jelínek, K. Z., Particle size analysis Translation editor: Bryce, W. A. J., (ed.), Halsted Press New York, 1974.

[15] Barth, H. G., (ed.), Modern methods of particle size analysis. Wiley, New York, 1984.

[16] Hagiwara, I., Tokuhiro, A., Oduor, P. G., Natural convection heat transfer of hydrophilic particle suspension: Implications on nuclear waste remediation, International Journal of Heat and Mass Transfer, 78 (2014), pp. 636-647.

[17] Bevington, P. R., Data reduction and error analysis for the physical sciences. McGraw-Hill. New York, 1969. 